\title{
Kidney Paraganglioma
}

National Cancer Institute

\section{Source}

National Cancer Institute. Kidney Paraganglioma. NCI Thesaurus. Code C159226.

An extremely rare parag ang lioma that arises from the renal hilum. Parag ang liomas that arise from the perihilar sympathetic gang lia are not included in this category. 